\title{
The Use of Pressurized Bladders for Stress Control of Superconducting Magnets
}

\author{
Shlomo Caspi, Steve Gourlay, Ray Hafalia, Alan Lietzke, Jim ONeill, Clyde Taylor, and Alan \\ Jackson
}

\begin{abstract}
LBNL is using pressurized bladders in its high field superconducting magnet program. Magnet RD3; a $14 \mathrm{~T}$ race track dipole; has been assembled and pre-stressed using such a system. The bladder, placed between the coil pack and the iron yoke, can provide $70 \mathrm{MPa}$ of pressure while compressing the coil pack and tensioning a $40 \mathrm{~mm}$ thick structural Aluminum shell. Interference keys replace the bladder's functionality as they are deflated and removed leaving the shell in $140 \mathrm{MPa}$ of tension. During cool down, stress in the shell increases to $250 \mathrm{MPa}$ as a result of the difference in thermal expansion between the Aluminum shell and the inner iron yoke. A number of strain gauges mounted onto the shell were used to monitor its strain during assembly, cool-down and testing. This technique ensures that the final and maximum stress in the shell is reached before the magnet is ever energized.

The use of a structural shell and pressurized bladders has simplified magnet assembly considerably. In this paper we describe the bladder system and its use in the assembly of a 14T Nb3Sn magnet.
\end{abstract}

Index Terms-bladder, pressurize, stress, superconducting.

\section{INTRODUCTION}

Lorentz forces generated by high field dipole magnets are too large to be handled by self-supporting collars. Experience with Nb3Sn magnets has shown that replacing the collars with a thin spacer and using structural rings or wire wrap over the yoke improves the magnet structure. In the past, two different techniques have been tried. Magnet D20 [1]; a 13 T dipole; was assembled by wrapping a high-tension stainless steel wire over the yoke. In contrast, a shrink fit structural Aluminum tube was used in the assembly of Twente University $12 \mathrm{~T}$ dipole magnet [2]. In both cases the final pre-stress results were less than desirable even though attempts were made to assure high tolerances.

\section{A. PRESSURIZED BLADDER SYSTEM (PBS)}

However, it became apparent that if we want high prestress, good control during assembly and a cost affective magnet, a change of course would be required. We need to identify ways to generate measurably large forces in combination with relaxed coil tolerances.

Using a hydraulic bladder system meets these three goals. An inflated bladder is a "smart shim" that compensates for low tolerances and can deliver large forces. Consequently

Manuscript received September 16, 2000.

This work was supported in part by the Director, Office of Science. Office of High Energy and Nuclear Physics and Director, Office of Science. Office of Basic Energy Sciences under U.S. Department of Energy Contract No. DE-AC03-76SF00098. there is no need for intermediate collars and pre-stress is delivered directly from the bladders and keys to the structural shell. Determining the stress of the shell can easily be done by measuring its strain. Bladders can be pressurized with melted liquid metal, as was done in the assembly of an ECR sextupole [3], or; as it was accomplished here; with the use of high water pressure and interference keys.

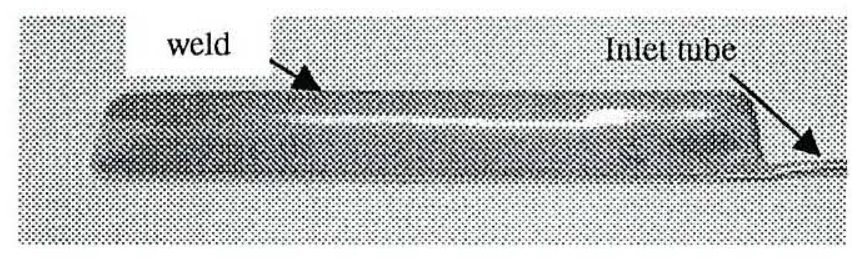

Figure $1 \mathrm{~A}$ bladder made from welded stainless steel sheets. The inlet tube is seen at the lower right corner.

Bladder technology was tested with a series of small bladders $(25 \mathrm{~mm}$ wide by $150 \mathrm{~mm}$ long), made from two $0.254 \mathrm{~mm}(0.010$ ") thick stainless steel sheets, with a $1 / 8$ " stainless tube (0.2" wall) as a supply line.

Initially, bladders were welded by hand, but as progress was made an outside shop was used to laser weld them. The final main bladders used in RD3 were $190 \mathrm{~mm}$ wide and 890 $\mathrm{mm}$ long. Its internal pressure and the compliance of the coils and structure control the overall bladder gap-size.

\section{B. BLADDER TEST}

The range of a reliable gap-size as a function pressure was determined experimentally. The maximum pressure a bladder can sustain before it bursts is a function of its stroke (the gap between the two sheets). To determine the bladder characteristic curve (for 0.010 " thick stainless steel sheet) bladders were placed within a known gap between two stainless steel beams. The beams were bolted and held in a press. Using a hand pump the water pressure was raised to 70$85 \mathrm{MPa}(10-12 \mathrm{Kpsi})$. Several times during the test the bladder was deflated and the gap size increased. The pressurization process was repeated until a burst occurred. Results are plotted in Fig. 2. Test bladders could be pressurized to $70 \mathrm{MPa}$ at $3 \mathrm{~mm}$ without failure. Some bladders survived at $6 \mathrm{~mm}$ gap and $70 \mathrm{MPa}$ (over $800 \mathrm{MPa}$ of tensile stress on the stainless steel sheets). Bladders that could sustain high pressure and large gap size usually failed somewhere along the weld; poor performing bladders tended to fail near the supply line. No special provisions were made to round the bladder's corners and we have not experienced 


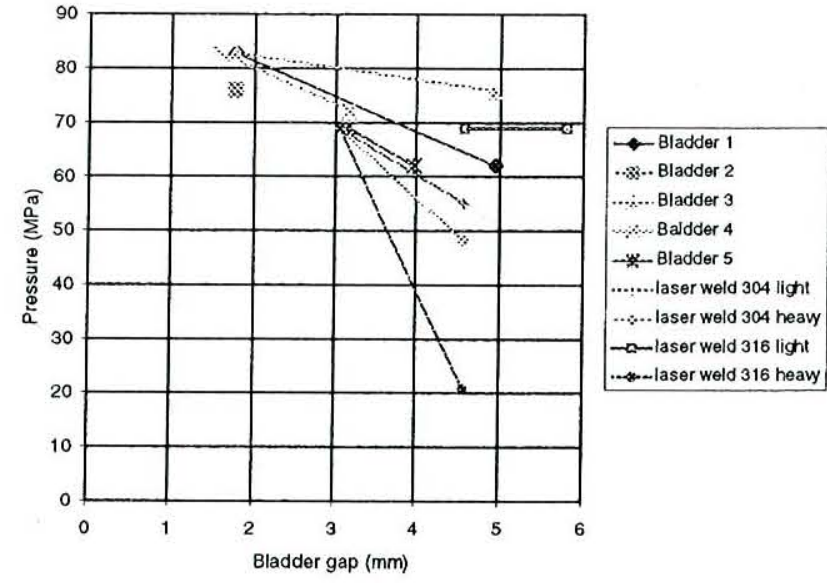

Figure 2 Pressure sustained by the bladder as a function of its gap.

any difficulties at those locations.

\section{Hydraulic System}

Final magnet assembly used a commercial air driven pump system (Fig. 3), capable of delivering pressures up to 200 $\mathrm{MPa}$.

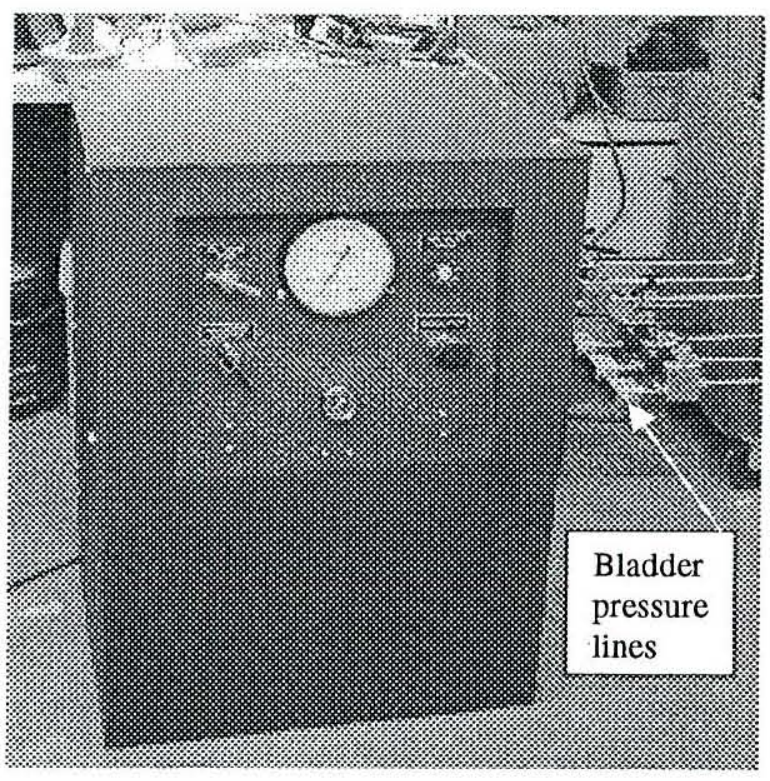

Figure 3 Bladder pressurizing unit.

\section{RD3 ASSEMBLY}

\section{A. Dipole magnet RD3}

Magnet RD3 is a Nb3Sn common coil dipole expected to reach 14 Tesla in a $10 \mathrm{~mm}$ bore. At that field the average Lorentz side force is $15.4 \mathrm{MN} / \mathrm{m}$ (a total of $12.0 \mathrm{MN}$ over the $780 \mathrm{~mm}$ coil length). A force of such magnitude can not be managed with a cantilever beam structure and tie-bolts as it was done in RT1. Further, a cantilever structure will not prevent the coils from separating over the gap. The requirement for no coil separation, large forces, a fragile $\mathrm{Nb} 3 \mathrm{Sn}$ coil and the need for reliable stress control made the use of bladders quite attractive.

The magnet is assembled from three sub-assemblies - a pre-assembled coil pack, a pre-assembled iron yoke and shell, and a set of keys and bladders (Fig. 6). The coil pack (Fig. 4) is an assembly of two inner coils, two outer coils (previously tested as RT1) and outer pads (iron). The coil-pack was preassembled and compressed with threaded pad-to-pad tie-rods. The iron yoke and shell were also pre-assembled in the vertical position and locked with temporary keys. The final magnet assembly of the coil pack and shell took place horizontally. Finally, bladders were inserted between yokes and pads with shims and special removable slip planes (to help during bladder extraction). As a precautionary measure auxiliary bladders were also used in the regions shown in Fig. 4. Bladders were inflated incrementally and temporary keys inserted every 15-20. MPa. After a final pressurization; corresponding to $85 \mathrm{MPa}$, final keys (1.5 mm thick) were inserted and the bladders deflated and removed with the aid of slip planes. The strain of the retaining Aluminum shell was measured continuously.

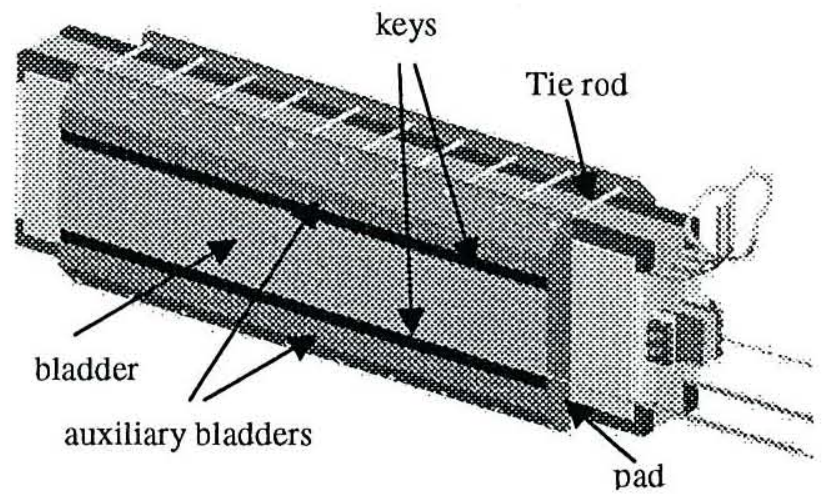

Figure 4 The coil pack is an assembly of coil modules between iron pads. On the pads facing away from the coils are key slots. Bladders are placed between keys

\section{B. Concept of Operation}

The balance of forces between the shell and coils takes place in several steps. Initially the shell pre-stress value is set at $150 \mathrm{MPa}$ by the bladders and keys. During cool-down the stress increases to its final value of $250 \mathrm{MPa}$ and remains unchanged during operation. The reason for that can be explained as follows (Fig. 4). Forces on the shell at point A are balanced by reactive forces between the two symmetrical halves of the magnet (point B). We expect most of the force to be carried in the iron post. The Lorentz forces unload the coil post and side rails and the shell is not expected to see any change until the post is completely unloaded. 


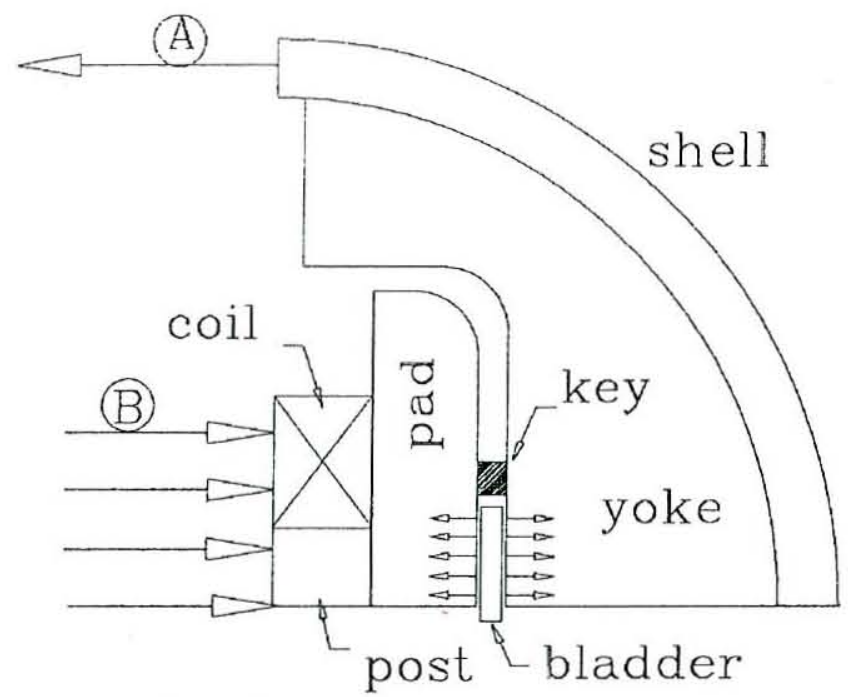

Figure 5 Forces related to RD3 magnet assembly

\section{STRUCTURAL SHELL}

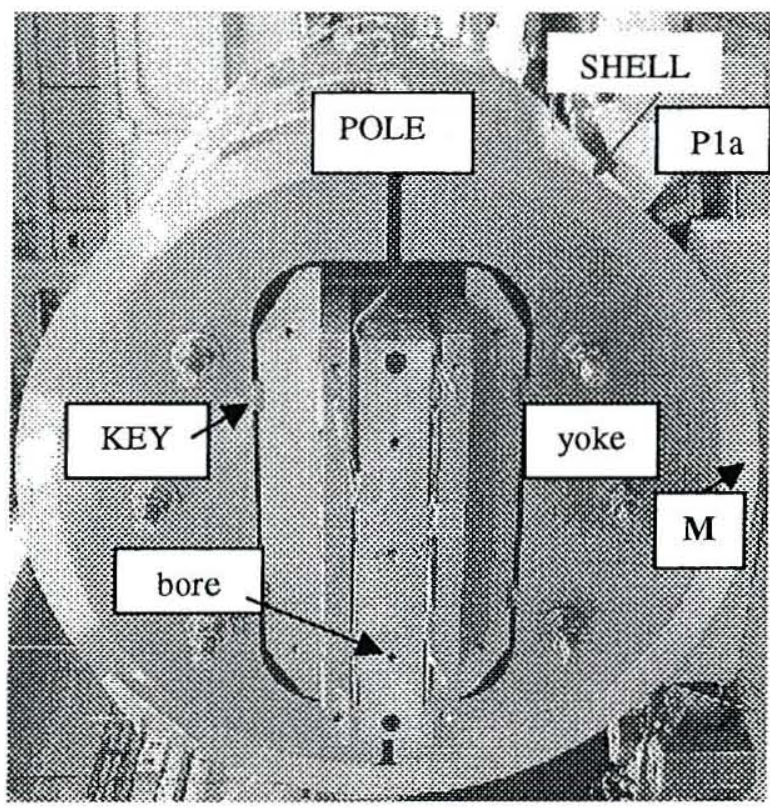

Figure 6 End view of RD3 showing the Aluminum shell, iron pads and yokes, 3 coil modules and keys between yokes and pads.

\section{A. Mechanical Model}

In order to test the bladder in a geometry that is similar to RD3 we built a 1/3 scale mechanical model. We used a 6061 T6 aluminum tube $(240 \mathrm{~mm}$ OD, $12.6 \mathrm{~mm}$ wall, $305 \mathrm{~mm}$ long) and standard off-the-shelf iron (equivalent to 1018). The yoke and pads were cut from 2" thick iron plates using an Electrical Discharge Machine (EDM). A simulated coil pack was made from aluminum blocks and an iron post clamped inside iron pads and tie rods (similar to Fig. 4). The shell was put into tension using two bladders and a hand pump. Water pressure in the bladders was raised to $80 \mathrm{MPa}$ before iron keys were inserted. After cool down to $4.2 \mathrm{~K}$ the shell reached a final pre-stress equivalent to a field of $15 \mathrm{~T}$. We have concluded that the measured strain of the shell followed closely an ANSYS two-dimensional plane-stress model with friction. The strain-stress relations of the mechanical model and magnet RD3 are the same, but the size of the forces and displacements are different. The similarity between the two cases and the fact that, with proper key size, Lorentz forces should not contribute to an increase in the shell stress after the magnet is energized, makes the test results of a mechanical model identical to those obtained during the final magnet assembly. Pressurizing the bladders strain the outer aluminum shell. Strain gauges installed around the shell can be calibrated directly against the bladder pressure and compared with those calculated with the program ANSYS.

\section{B. Magnet RD3}

The RD3 shell was machined from a 2219-T852 Aluminum forging (740mm OD, $40 \mathrm{~mm}$ wall and $890 \mathrm{~mm}$ long). The iron yoke laminations were cut from 2" plates using a water jet with a final machining. During assembly the shell strain was measured at all symmetrical points corresponding to $\mathrm{M}, \mathrm{P} 1 \mathrm{a}$, and P1. Location P1 was instrumented both at its OD and ID.points. Several gauges were instrumented to read strain in the axial direction. The measured strain at location $\mathrm{M}$ is plotted against the bladder pressure in Fig. 7. The horizontal data points correspond to the shell unloading and loading on temporary keys. Final size keys of $1.5 \mathrm{~mm}$ were used corresponding to a shell strain of 1830 microstrain. When the results are compared with ANSYS, the measured strain agrees well when a friction factor of 0.15 is applied between the yoke and the shell. That friction factor was down from a value of 0.25 observed in the mechanical model and in agreement with the improved surface quality used in the magnet parts. Location P1 at the pole area was instrumented at both ID and OD locations. With the understanding that the shell will undergo bending at that point we expected local yielding along the pole ID. The choice to allow local yielding was a way to avoid making the shell oval which would have resulted in a shell that is costly and more time consuming to make. Point P1a represented a location that is both bending free and free from friction effects.

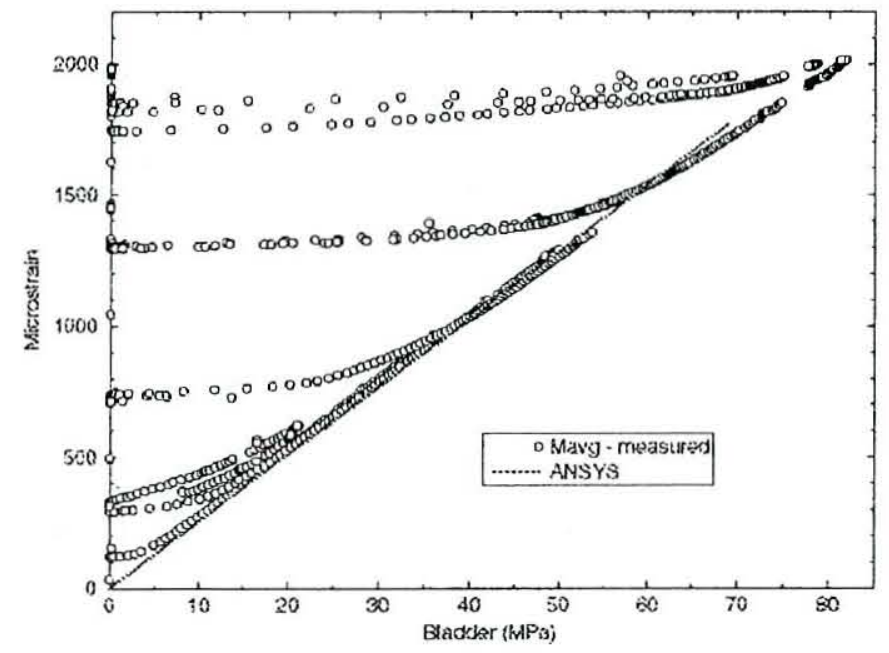

Figure 7 Strain of shell at point $M$ during bladder operation. 
Table I Shell stress-strain during assembly

\begin{tabular}{|c|c|c|c|c|}
\hline LOCATION & \multicolumn{2}{|c|}{ RD3 MEASURED } & \multicolumn{2}{c|}{ ANSYS } \\
\hline & $\begin{array}{c}\text { STRAIN } \\
(\text { MIC) }\end{array}$ & $\begin{array}{c}\text { STRESS } \\
(\text { MPA })\end{array}$ & $\begin{array}{c}\text { STRAIN } \\
\text { (MIC) }\end{array}$ & $\begin{array}{c}\text { STRESS } \\
\text { (MPA) }\end{array}$ \\
\hline MOD & 1834 & 143 & 1770 & 138 \\
\hline P1A & 2020 & 157 & 2134 & 166 \\
\hline POD & -657 & -67 & 0 & 0.1 \\
\hline PD & 5120 & 400 & 4115 & 321 \\
\hline
\end{tabular}

Magnet assembly with bladders required no more than a couple of days. As shown in Fig. 8 only about $10 \%$ of strain loss occurs after the bladders are deflated. It is also apparent that there is no creep and the magnet structure maintained its strain many days following the assembly. During cool down we expected the strain in the shell to double. At $4.2 \mathrm{~K}$ the strain increased to a measured value of 3420 microstrain compared with 3461 calculated by ANSYS (Fig. 9). That strain is equivalent to a stress of $267 \mathrm{MPa}$ in the shell. As the magnet reaches its final field of $14 \mathrm{~T}$ we expect the shell to remain at that stress level and all inner coils to remain in contact (e.g. no coil separation as seen during the RT1 test

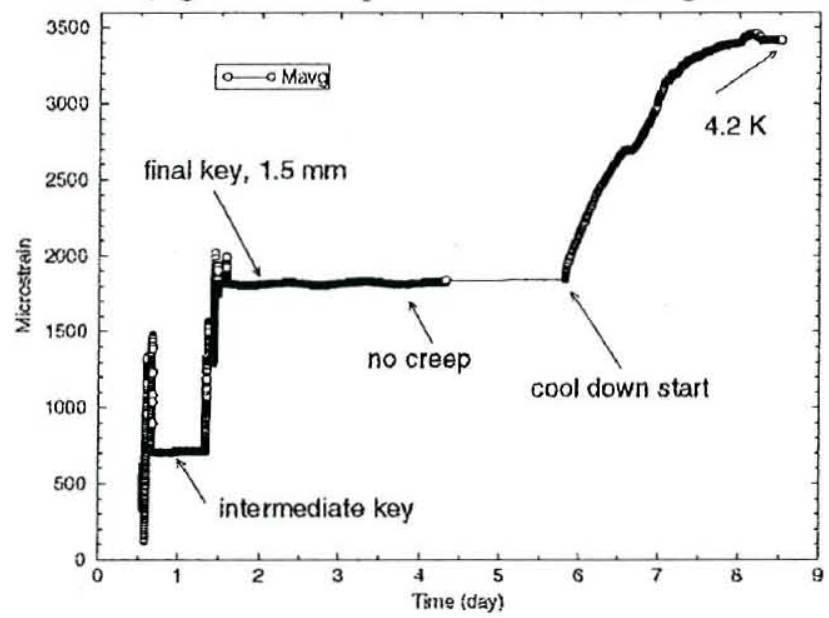

Figure 8 Strain as a function of time measured on the shell at point M.

[5]).

\section{CONCLUSION}

We have demonstrated the use of high-pressure bladders in the assembly of high field superconducting magnets. Such a system can deliver a well-controlled pre-stress level to both coil and structure regardless of tolerances. This method also ensures a similar straightforward operation during magnet disassembly.

\section{ACKNOWLEDGMENT}

We are grateful to Roy Hannaford, Jim Swanson, Nate Liggins, Paul Bish, Hugh Higley, Evan Palmerston and Doyle Byford whose hard work and dedication keeps us all motivated.

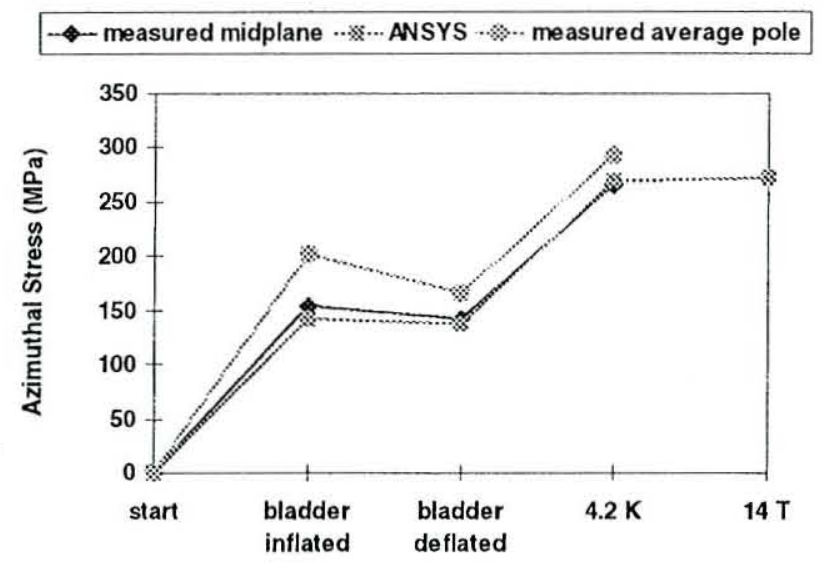

Figure 9 Stress of shell at various times.

\section{REFERENCES}

[1] S. Caspi, K. Chow, D. Dietderich, A. Lietzke, A. McInturff and R. Scanlan "Development of high field dipole magnets for future accelerators," Proceedings of 15 International Conf. On Mag. Tech.,Beijing China, pp 51-54, Oct. 1997.

[2] A. den Ouden et al. "An experimental 11.4 T Nb3Sn LHC type of dipole magnet," IEEE Trans. Mag. Vol. 30, pp. 2320, 1995.

[3] C. Taylor, S. Caspi, M. Leitner, S. Lundgren, C. Lyneis, D. Wutte, S. T. Wang and J. Y. Chen "Magnet system for an ECR ion source," IEEE Trans on Applied Superconductivity., vol. 10, No. 1,pp. 224227, March 2000

[4] S. Caspi, M.Fong, S.Gourlay, R. Hafalia, A. Lietzke and J. Oneill, "RD3 Structure," SC-MAG 725, Lawrence Berkeley National Laboratory, June, 2000.

[5] S.Gourlay et al. "Fabrication and test of Nb3Sn racetrack coils at high field," this conference. 